\title{
Slesvig og Risby.
}

Ofte hænder det, at større Kredse af Landsbykirker kán grupperes om den Domkirke, der har været deres kunstneriske Midtpunkt. Det gælder navnlig i den tidlig romanske Periode for hele den jydske Halvø, og det gælder ikke mindst for Sønderjylland. Da Domkirken i Slesvig blev rejst som en romansk Brudstenskirke, kunde den afse Haandværkere og Stenmestre til de omliggende Smaabyer, hvor vi nu. navnlig i Angel, kán opspore en hel Række Søjleportaler, hvis Forbillede det ikke volder Vanskelighed at bestemme. ${ }^{1}$ )

Men Slesvigkirken fik jo ikke Lov til at forblive en romansk Pillebasilika. Enten den nu ikke fuldendtes helt $i$ denne Skikkelse, eller den underkastedes en fuldstændig Ombygning, saa har man i al Fald i tidlig Teglstensperiode ganske forandret dens oprindelige Karakter, og det Sporgsmaal er unægtelig nærliggende, om ikke ogsaa denne storartede Byggevirksomhed har sat sit Præg paa Omegnens Landsbykirker.')

Overskriften til denne lille Artikel antyder, i hvilken Retning Spørgsmaalet tænkes besvaret. Afstanden mellem Slesvig og Risby, der ligger i Svansen ved Sliens sydlige Bred, maaler kun 17 km. i lige Linje. Og da der ved Risby Kirke akkurat som ved Domkirken er blevet bygget med Tegl $i$ iden romanske Stilperiode, er det fristende at stille netop disse to Arbejder sammen. Der er blot den Hage ved det, at vi paa det foreliggende Grundlag ikke godt kan foretage en saadan Jævnføring. Den pyntelige, elegante, lille Landsbykirke og den store Domkirke har næppe to Træk tilfælles, der kan berettige os til at kæde dem sammen. Men dette er sikkert kun en Tilfældighed og hænger sammen med, at Arkitekten ved den lille Risby Kirke ifølge Sagens Natur har maattet lægge den dekorative Vægt paa det Ydre, mens ved Domkirken lige omvendt det Ydre er gaaet tabt ved senere Ombygninger, og kun det Indre staar nogenlunde velbevaret. Det kan i Virkeligheden bevises, at disse to. 
Bygninger hører sammen. De er ikke blot bygget paa samme Tid, men ogsaa af samme Arkitekt, og det er endda muligt at identificere denne Mand, ikke hans Navn, men hans øvrige Gerning. Det er dette,

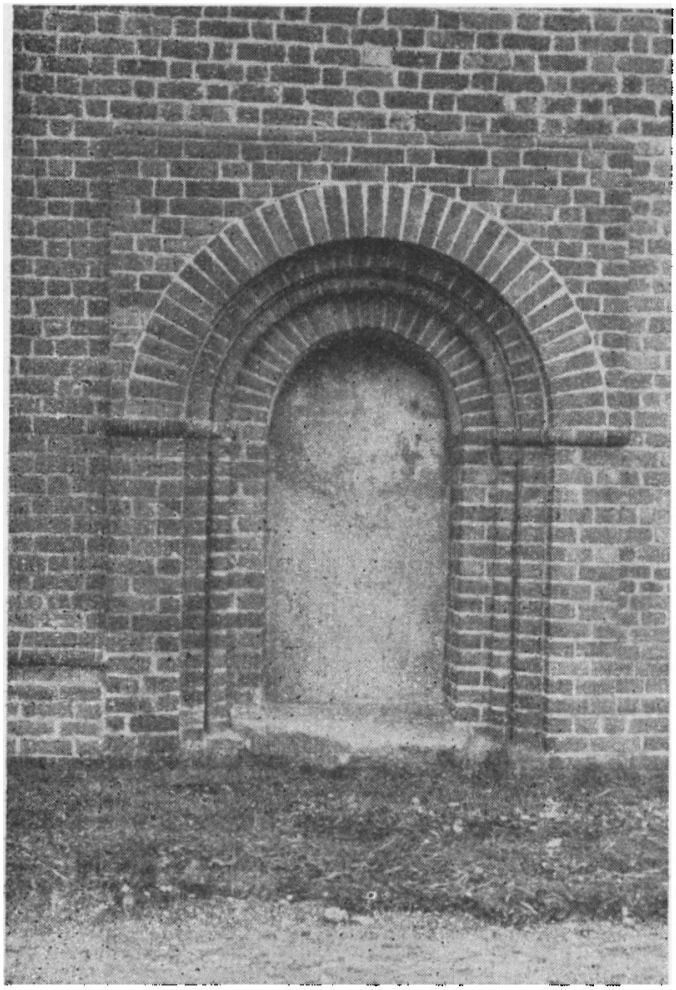

Fig. 1. der nærmere skal undersøges i denne Artikel.

Teglstensarbejderne ved Slesvigs Domkirke falder i flere Afsnit. Til de ældre Partier af Tegl maa regnes de ombyggede Korsarme, væsentlig disses ovre Dele, der baade i Stil og Teknik skiller sig ud fra Skibet. Langkirkens ostlige Fag danner det næste Afsnit, og samtidig er vistnok Korsskæringens og Korsarmenes Hvælvinger sat op. Derefter har Arbejdet ligget stille $i$ nogen Tid, indtil man i tidliggotisk Stilperiode fuldendte de tre Vestfag, delvis efter Mønster fra Østfaget, og satte de ottedelte Hvælvinger op. ${ }^{3}$ )

Hverken de senmiddelalderlige Ombygninger eller Korsarmene, der synes at have Tilknytning til den tidlig danske (sjællandske) Teglstenskunst, skal nærmere omtales her. Det er egentlig kun Skibets østlige Fag, vi kommer til at beskæftige os med. Vi ser ved forste Øjekast, at vi her staar overfor en fremmedartet Arkitektur. Det ses af Glasurtekniken, der her er rigelig anvendt (omend for en stor Del fornyet); det 
ses af Riflingen, ider er af en anden Art end den, der anvendtes i den øvrige hjemlige Teglstenskunst. Hovedsøjlernes Kapitæler ligner ikke det danske Trapezkapitæl, og selve Planen for Nybygningen, det bundne Hvælvingssystem, er noget nyt herhjemme. I dette System svarer der to $\mathrm{Si}$ deskibsfag til hvert Midtskibsfag. Hveranden af Pillerne skal bære Skjold- og Gjordbuerne og maa derved yderligere forstærkes, mens atter de øvrige af Midtskibets Piller gaar fri og følgelig kan gøres meget svagere. Systemet, der spiller paa en rolig Rytme mellem svage og stærke Partier, er vel ikke ganske ukendt herhjemme, men i den særlig slesvigske Form - der senere er blevet delvis odelagt ved Ombygnin-

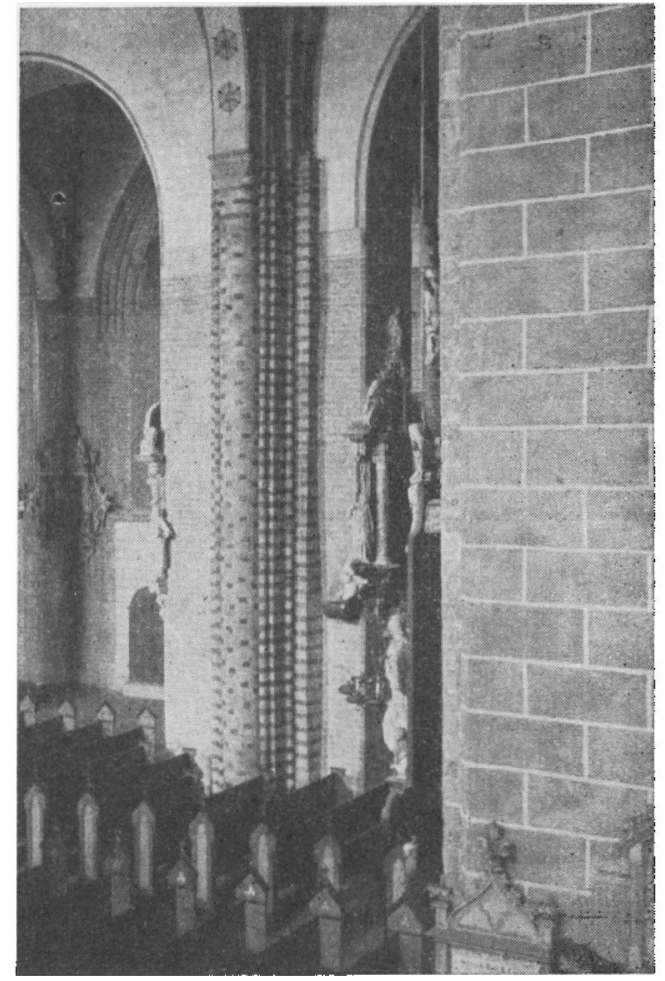

Fig. 2. Slesoigs Domkirke. Nordre Midtskibspille. gen $i$ det 15. Aarh. - er det dog en Sjæeldenhed.

Her i Slesvig Domkirke tog man sit Udgangspunkt i den gamle Basilika. De to forste Arkader i den gamle Kirke, regnet fra Korsskæringen, udgjorde mod Nord og Syd Siderne i det nye Midtskibsfag. Det andet Pillepar, stadig regnet fra Korset, forstærkedes med en svær Halvsøjle, flankeret af to slanke Stave, alt af Tegl (Fig. 2). Den nuværende moderne Bemaling svarer næppe til de oprindelige Forhold. Overalt, hvor man kan komme det gamle Murværk tæt ind paa Livet - 
bedst ved den godt belyste nordre Pille -, ses der Spor af grønlig Glasur, saadan som det ogsaa ses paa de øvrige Piller længere mod Vest.

Den nødvendige Følge af en saadan Iagttagelse er da, at man maa forestille sig den gamle Slesvigkirke indkapslet i en skal af grønglaserede Teglsten. Man kan nu kun ane, hvor dejlig Virkningen har været. - Denne Murstensteknik i Forbindelse med en kraftig Rifling af Nordpillens Sten - en Rifling, der stik imod al dansk Sædvane er foretaget $\mathbf{i}$ det bløde Ler $f ø r$ Brændingen - viser tydelig hen til Nordtysklands tidlige Teglstensarkitektur. Ogsaa der finder vi det bundne System. Det findes f. Eks. i Lübeck Domkirke, og i Forbindelse med den fra Slesvig kendte Murstensteknik har det sin fornemste Repræsentant i Ratzeburg Domkirke, hvorfra det har bredt sig til Omegnens Kirker i Lauenburg og Østholsten, f. Eks. Mölln, Eutin og Altenkrempe. At Slesvig har saadanne Fæller sydpaa, understreges yderligere af det omtalte Pillepars Kapitæler, der ikke efter dansk Sædvane er Trapez-, men Trekantkapitæler, der - som Navnet antyder - fortil præsenterer en ligebenet Trekant med Grundlinien oppe under Dakpladen (Abakus) og Spidsen pegende nedad mod Jorden. Thi denne Kapitæltype er særlig nordtysk. ${ }^{4}$ ) Dækpladens Former taler samme tyclelige Sprog, og naar man i Kikkerten har opfanget de slanke Søjlestaves smaa Kapitæler, maa man erklære sig for overbevist. Thi det er den Kapitæltype, som Tyskerne kalder »Klauenkapitell«, og som kan nøje afgrænses inden for bestemte Dele af Nordtyskland. Fra den firkantede Dækplade udgaar Hjørneblade, der som skarpe Kløer griber ned om Kapitælets Skaal; derfra Navnet Klo-Kapitæl. ${ }^{5}$ )

Det er paa Forhaand givet, at vi skal søge Slesvig Domkirkes Frænder blandt disse nordtyske Kirker, og da rykker særlig Domkirken i Ratzeburg frem i første Række. Men vi vilde næppe kunne komme videre end til at konstatere almindeligt Slægtskab og Samtidighed, hvis ikke en Landsbykirke ved Sliens sydlige Bred kom os til Hjælp. 
Den ualmindelig nydelige lille Teglstenskirke i Risby er bygget i romansk Till og bestaar af Skib, Kor og Apsis. Den er senere blevet udvidet vestpaa. Ft Træatarn lakker Vestgavlen, og paa Sydsiden af Koret er der en meget sen Tilbygning. Skib og Kor hviler paa en Sokkel med Rundprofil og Skraikant. Alle Iljørner indrammes af Lisener, der paa skibet springer starkt frem. Brgge Skibets Dore ses nu efter lengenncmgribende Rastauration kort for Verdenskrigen i starkt fornyet Skikkelse, mru holdigrvis er det stadig muligt overalt at spole rlo gamle, agte Sten mellem alle de nye og rlerverl konstatere, at Fornyelson i alt vasentligt er forsvarlig genuemfort. - Dørene har siddet tiet hen til den forsvundne Vestyavl. Alle Vinduerne,

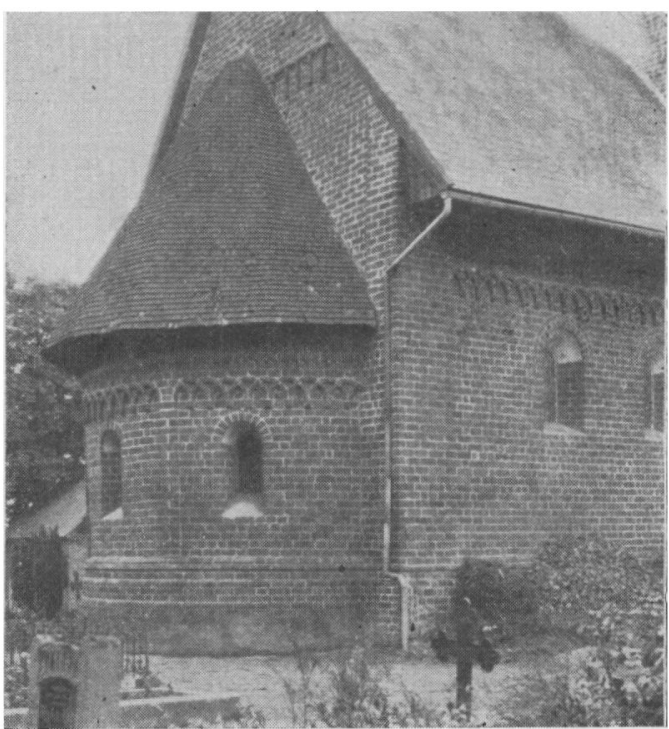

Fig. 3. Risby Kirkes Korslutning. hvoraf cler i Skibet har varet 3 3, har siddet (1st for Portalerne. Nu er kun to pai Nordsiden i Behold; der er Spor af et rnkelt paa Sydsiden. Nordvinduernes Oversving er pudset og malet i IRudemønster, noget der ikke er ukendt i Nordtyskland. ${ }^{6}$ ) Vinduerne er smaa, rundbuede, hojtsiddende og har uprofilerede skraa Karmsider.

Til den kraftige Lisenkonstruktion svarer paa Skibets Nort- og Syaside Friser med samme Fremspring. Mod Syd er der en dobbelt krydsende Rundbuefrise paa Konsoller af afrundede Sten, mens Nordsiden har en mærkelig, ligeløbende Konsolfrise, bestaaende af smaa, stavformede Dværgsøjler.

Koret har 2-2 Vinduer, men de er kun nogenlunde i Behold paa Nordsiden, hvor de er stærkt fornyede. De to østlige Lisener omklamrer Korets Hjørner og er paa Ostgavlen forlænget saa højt op, 
at de overskares af Tagets Skraalinjer, forløber uden Funktion, mens de paa Nord- og Sydsiden løber ud i dobbelt, krydsende Rundbuefriser. Paa Korets Østgavl (Fig. 3), paa begge Sider af Apsis' spidse Kegletag, ses en Stump Konsolfrise lige som paa Skibets Nordmur, og allerøverst oppe ses det samme Motiv gentaget, men omvendt: Dværgsøjlerne rejser sig lodret op fra en vandret Rundstav (ses ikke paa Billedet Fig. 3).

Apsis hviler paa en Sokkel, der har dobbelt afrundet Led under en smal Rundstav og overst en Skraakant. Der er tre Apsisvinduer, adskilt ved to Kvartstenslisener, som barer den dobbelte, krydsende Rundbuefrise.

Under Gennemgangen af Kirkens enkelte Led finder man flere Træk, der kendes fra den øvrige danske Teglstensarkitektur. Kendt er saaledes baade Lisenerne og Buefriserne (fra Lolland-Falster), mens Søjlefrisen - i al Fald i denne Skikkelse - er mig ganske ukendt baade i Danmark og Udlandet. Det fremmedartede viser sig tydeligst ved Portalerne paa Skibets Nord- og Sydside. Det er da ogsaa dem, der bringer os. paa Spor af Bygmesteren.

Den simpleste af Dørene er den mod Nord. Den sidder i et Halvstensfremspring og aabner sig indad med to dybe False, hvoraf den inderste har en svær Rundstav, der over Kapitæl og Kragbaand fortsætter hele Buen rundt (Fig. 1). Der er ingen Basis. Kragbaandet har et enkelt Rundprofil. Kapitælet er blot et Skifte højt, men det er et Klo-Kapitæl, og det er vigtigt i denne Forbindelse. - Rigere og større er Sydportalen. Den sidder $i$ et bredt Murfremspring med profilerede Kanter. Det er i Virkeligheden Sokkelprofilet, der som en mageløs Ramme bugter sig uden om Portalfremspringet. - Ligesom Nordportàlen har denne en Dobbeltfals med Rundstav og Klokapitæl (Fig. 4).

Dette Kapitæl, som vi forst lærte at kende inde i Slesvig Domkirke, findes baade i Holsten og det ratzeburgske og er afgort af nordtysk Oprindelse. I Danmark findes det ellers kun i de Egne, der har haft nordtyske Tendenser, f. Eks. Lolland, hvor det endnu kan ses i flere af de ældste Kirker: Tir- 
sted, Holeby, Øster Ulster og andre.') Men ikke blot Kapitælerne, ogsaa Risbyportalens hele Indramning peger sydpaa. Denne flot opsatte Ramme med Modsatningen mellem de stramme Skraakanter og de blode runde Led findes, saavidt jeg ved, kun to Steder uden for Risby, nemlig i Diesdorf og Forhallen til Domkirken i Ratzeburg (Fig. 5-6). Det bliver den sidste, vi maa standse ved. Fra to Sider, først fra Slesvig og nu fra Risby, har vi kunnct pege paa Domkirken i Ratzehurg som Forbillede, og man sparger sig selv, om ikke ogsaa selve Bygmesteren er hentet der. Selv en overfladisk Betragtning af den ratzeburgske Indgangshal rober, at noget maa der være on det. Vi genfinder den kraftige Lisenkonstruktion og starkt

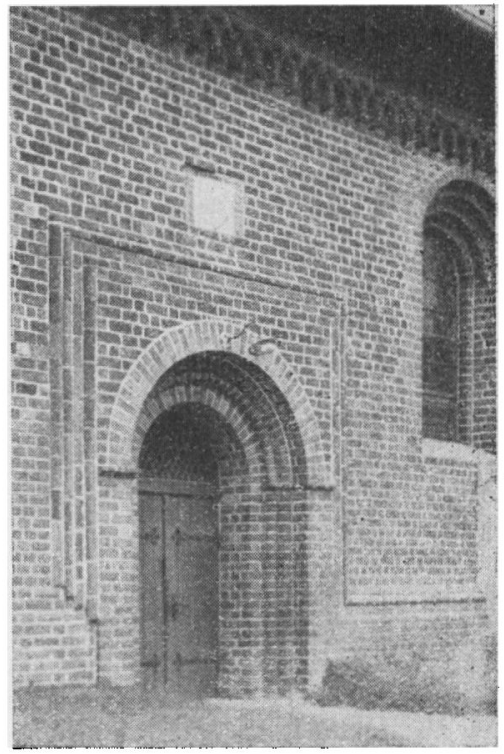

Fig. 4. Risby Kirkes Sydportal. fremspringende Krydsbuefrise.

Men vi ser ogsaa, at baade denne norltyske Bygning og Risby Kirke er rejst i polsk Skiftegang (med Løber + Binder i hvert Skifte, ikke som ved Munkeforbandt med Laber + Løber + Binder), hvad der er en afgjort Sjældenhed i Teglstensarkitekturen paa hine Tider. Altsaa er vi berettigede til at tale om Slægtskab, meget nært Slægtskab, mellem Risby og Ratzeburg og maa da nødvendigvis inddrage sidstnævnte $i$ vor Undersøgelse.

Desvarre maa man straks rykke frem med et kraftigt Forbehold: Domkirken i Ratzeburg er endnu ikke behandlet i Literaturen efter Fortjeneste. ${ }^{y}$ ) Saaledes trænger vi endnu til en nøjagtig Datering, som kun en detaljeret Gennemgang af Bygningshistorien og en samlet Behandling af den nordtyske Teglstenskunst kan give. Vi maa give Afkald paa begge Dele. 
$\mathrm{Nu}$ stiller det sig saa heldigt, at vi kun behøver at beskæftige os med Bygningens seneste Parti, nemlig Forhallen, men hvornaar er den saa rejst? Selve Kirkebygningen maa være samtidig med Domkirken

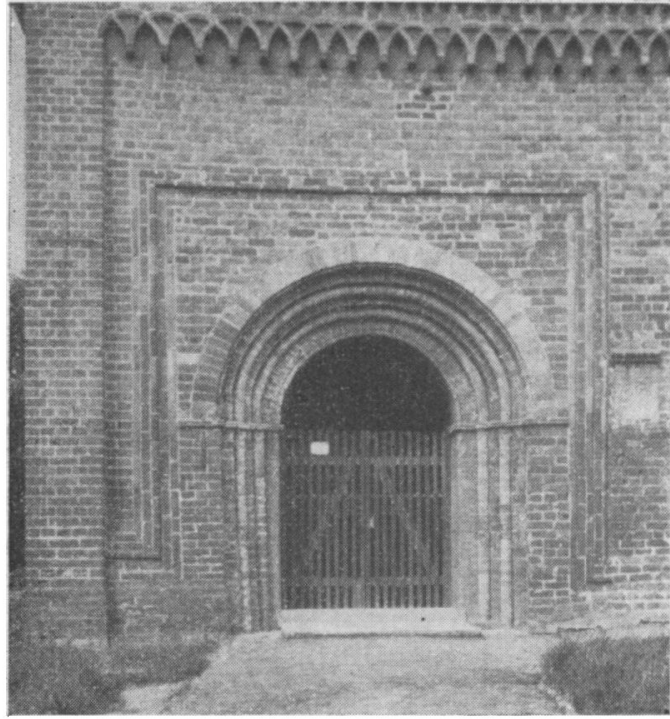

Fig. 5. Domkirken i Ratzeburg. Forhallens Portal.

i Lübeck og kan næppe være paabegyndt senere end 1170'erne, snarere noget tidligere, selv om det falder haardt at folge Richard Haupt, naar han sæetter Begyndelsesaaret til 1154. ${ }^{\circ}$ )

En Donkirke af denne Storrelse kan umulig være rejst paa een Gang. Der maa have været standsninger i Arbejdet, og det er ikke ugorligt at spore Forandringer i stilen fra det ene Bygningsafsnit til det andet. Men taget under eet er der ingen større Brud at spore. Alle væsentlige Træk fra Apsispartiet genfindes mod Vest, og kun Forhallen skiller sig ud, samtidig med, at den bibeholder vigtige Træk af Domkirkens Fysiognomi.

Det er en kvadratisk Bygning, rejst i polsk Skiftegang. Den har fire Hvælvingsfag, hvis Gjordbuer mødes i Midten, samlet og stottet af en rigtprofileret Pille. Oprindelig var der to Portaler, nu er kun den vestligste i Behold, mens den anden forsvarkd ved Kirkens Restauration 1875-81.10) Slægtskabet med Risby fremgaar udelukkende af Skiftegangen og det mærkelige Portalfremspring: det er Sokkelprofilet, der er bøjet om og lober lodret tilvejrs uden om Portalen. Der er dybe False med Rundstave og Klokapitæler, kun er alt her rigere og elegantere 
end i Risby, men der bør vel ogsaa være Forskel paa en Kathedral og en Landsbykirke. Det bringer heller ikke Forvirring i Billedet, at den pragtfulde Sydgavl i Ratzeburg ikke genfindes i Risby, hvor Vestergavlen jo forlængst er forsvundet. Domkirkehallens mærkelige Gavltrekant har slanke, lodrette Rundstave, der som et Paleværk ses paa Baggrund af Gavlfeltets Zigzag-Murværk, som atter indrammes af Sideliniernes Rund-

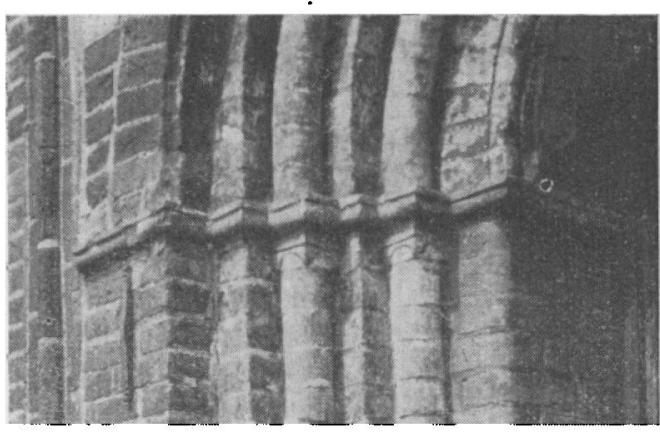

Fig. 6. Domkirken i Ratzeburg. Forhallens Portal. buefriser og gennembrydes af smaa kløverbladformede Vinduer. Rundstavene forlaber uden Funktion, men de midterste lober af paa en stor Cirkelblænding, hvori der er indskrevet mindre Cirkler paa glaserede Smaastave. Det er tydeligt nok Mindelserne om en Vinduesrose, og da en italiensk, dler har spøget i Bygmesterens Tanker.

En skrækkelig moderne Bemaling har ikke kunnet ødelægge Forhallens Indre, hvis Arkitektur er saa fremragende, at den slaar igennem alle Forklædninger. Det er Midtersøjlens fire sammenkoblede Halvsøjler, der uvilkaarlig fastholder Opmærksomheden (Fig. 7). Pillen er muret op af lyse og morke (glaserede) Skifter. Kapitæleme har den særlig nordtyske Trekant trædende frem i svagt Relief. Søjlerne adskilles af rode Teglstensstave med Klokapitæler, mens de vægfaste Piller har indfældede Hjørnestave med nydelige smaa Kapitæler, ofte med hosetter, indpressede $\mathrm{i}$ det bløde Ler for Bræudingen. - Det hele nydelige Interior- der $\mathrm{i}$ sin Finhed nødvendigvis maa paralleliseres med italienske, snarest lombardiske, Kirker som San Lorenzo i Verona, er jo ganske ukendt i Risby. Men i samme Øjeblik dette indrømmes, peger vi paa Slesvig Dom- 
kirke: der findes nemlig Mage til den ratzeburgske Fripille, blot koblet til Væggens Piller (Fig. 7). Den originale Experimenteren med Materialet, Skiften mellem Glasur og Ikke-Gla-

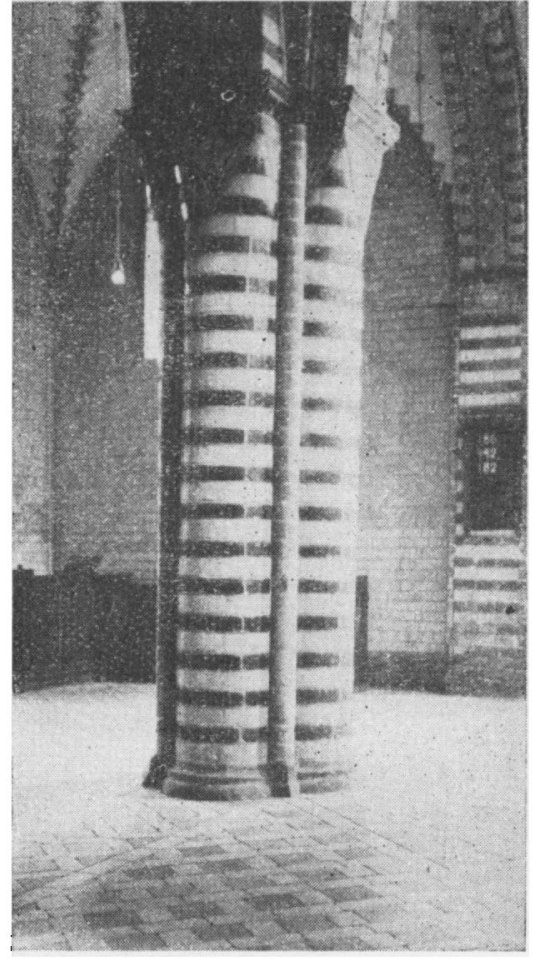

Fig. 7. Domkirken l Ratzeburg. Forhallens Indre. sur, maa i sin Tid have kendetegnet den nu lemlæstede Domkirke i Slesvig saavel som dens ratzeburgske Frlle. Endelig kommer hertil den særlige Riflingsteknik, som er kendt fra Ratzeburg i hele Domkirkens Udstrækning; denne Rifling er foretaget med kraftige, djarve Snit i det bløde Ler - sandsynligvis med en Trækam - før Bræudingen. Men netop denne Teknik findes, som ovenfor omtalt, i Slesvig Domkirke, og den fincles desuden paa flere andre danske Monumenter, der alle - direkte eller indirekte - har deres Forudsatninger $i$ holstensk og nondtysk Arkitektur. Man har antaget, at dens Forekomst i Danmark kunde suttes til Tiden omkring 13. Aarh.'s Midte. Sikkert nok ankom den her til Landet nogle Aartier for den Tid."

Resultatet af denne Undersøgelse kan saaledes sammenfattes i følgende. Baade i Slesvig og i Risby finder vi vasentlige Træk fra Domkirken i Ratzeburg, eller populært sagt: Slesvig og Risby sammenlagt giver Ratzeburg. Dette kan kun forstaas paa den Maade, at den nordtyske Arkitekt, der lagde den sidste Haand paa Domkirken i Ratzeburg, er blevet kaldt til Slesvig for at bygge videre paa Domkirken der, og under sit Ophold ved Slien har haft Lejlighed til at opføre den lille Landsbykirke i Risby. 
Hvorna ar? Det er et Spørgsmaal, man uvilkaarligt stiller sig selv: hvornaar har disse Bygningsarbejder fundet Sted? Helst vilde jeg være fri for at besvare det, da der over-. hovedet ingen positive Aarstal er at holde sig til. Der meldes ikke noget om, hvornaar Ratzeburghallen er bygget, den almindelige og om trentlige Datering ca. 1250 beror paa et rent Skøn og er desuden uforenelig med Bygningens hele Karakter. ${ }^{12}$ ) Det eneste helt sikre er, at den fastholder Traditionerne fra Domkirkens wldste Dage, altsaa fra 1170'erne, og da den endnu er romansk i alle væsentlige Træk, kan man skønne, at den næppe er meget yngre end Aarene omkring 1200. Hvad saa Slesvigkirken angaar, har Valdemar den Stores berømte Gavebrev sikkert givet Signalet til storartede Byggearbejuer, og det vil i første Omgang sige Korsarmene. ${ }^{13}$ ) Der er blevet fortsat med Skibet endnu i romansk Tid, og det var dette sidste Parti, der skyldtes den ratzeburgske Bygmester. Er Korsarmene fra 1180'erne eller derefter, kan Skibets Østfag tidligst være fra Begyndelsen af 13. Aarhundrede. Men ogsaa dette er altfor vagt, og man ser sig om efter andre Holdepunkter.

Paa Vejen mellem Slesvig og Ratzeburg findes der ingen Monumenter, som kan have bragt den nordtyske Stil til Sanderjylland. Altenkrempe er for sen, Segeberg (Klosterkirken) er for fremmedartet. Der er ganske sikkert Tale om direkte Import fra den fjerne By ved den idylliske Ratzeburger Sa; og er det først klaret, kan man ikke frigøre sig for den Tanke, at ledende danske Mænd inden for Kirke og Regering har været i Ratzeburg og der sørget for, at den begavede Arkitekt blev overfort til Slesvig. Ratzeburg blev erobret af Hertug Valdemar, den senere Valdemar Sejr, 1201. ${ }^{14}$ ) Mellem dette Aar og Ulykkesaaret 1223 kan man formode, at Arkitekten blev indkaldt, maaske af Kongen selv, maaske af Grev Albert af Orlamünde, der raadede over de nordalbingiske Lande i Valdemar Sejrs Navn, maaske af Kongens Kansler, Slesvigbispen Niels. Da Kunst ikke uden videre respekterer politiske Grænsedragninger, kunde den her gengivne Datering synes lovlig tidlig. Den er alligevel den sandsynligste. Man forstaar ellers ikke 
det lange Spring fra Ratzeburg til Slesvig. Men hvordan dette end skal forstaas: givet er det, at Ejderen nu var overskredet. Invasionen af nordtysk Arkitektur var begyndt.

Maaske er vor Ratzeburgermesters Skæbne ikke udtømt med disse Linier. Hans Spor peger ud over Sønderjyllands Grænser, ind $\mathbf{i}$ det egentlige Kongerige. Hans Stil afspejles med talrige Sidespring og stærk Lokalfarve - i de lollandske Kirker og i mesterlig Elegance i Aarhus Domkirkes Skib. Dette sidste overlegne Arbejde, nu sørgelig skæmmet, har han maaske været med til at rejse. Maaske - for det kan næppe nogen Sinde afgøres med fuld Sikkerhed.

I Aaret 1218 blev den unge Valdemar, Dronning Dagmars Søn, kronet og salvet i Slesvig Domkirke under Nærværelse af talrige Stormænd, baade Hertuger, Bisper og Abbeder. ${ }^{15}$ ) Stod Ratzeburgmesterens Part af Domkirken da færdig? Vi veed det ikke. Den var dog sikkert paabegyndt. Og hvis en og anden i denne store Forsamling har taget de nye Byggearbejder i Øjesyn, set hvordan det svage Lys fra Kirkeruderne gled hen over de tunge, grønglaserede Mure og spejlede sig i de svære Søjlers runde Legemer - mon han da har tænkt paa, at denne fremmedartede Arkitektur var Budbringer fra en ny Kultur, der her for Alvor brød frem over Ejderen og senere skulde blive skæbnesvanger for Landet omkring Sliens Bredninger -?

Jan Steenberg. 


\section{Noter.}

1) Mackeprang, Vore Landsbykirker (1920) S. 64. - Beckett, Danmarks Kunst I (1924) 118 ff.

$\left.{ }^{2}\right)$ Aarbøger for nord. Oldk. 1914 S. 124 (M a c k e p r a n g).

3) Muligvis har man forberedt Byggearbejder 1260: Erslev, Repertorium I 383 med Henvisning til Cypræus, Annales 283. - Hvis Kilden er til at stole paa, hentydes der vistnok til Vestpartiet og Midtskibets Hvælvinger.

- Zeitschrift für Geschichte der Architektur VI 83 (0 t to Sti e h l).

5) Richard Haupt, Die Bau- und Kunstdenkmäler in der Provinz Schleswig-Holstein VI 299, Fig. 334, og S. 367, Fig. 520-22. - Jeg kender ikke andre Eksempler fra Sønderjylland end dem i Domkirken og i Risby.

-) Mackeprang,Vore Landsbykirker 28, Fig. 11. - Skakbrætmotivet i Vinduernes Oversmig findes i Diesdorf.

7) Jfr. min Artikel i Lolland-Falsters hist. Samfunds Aarbog 1933.

8) Rickmann, Die Domkirche zu Ratzeburg (1881). - Ferd. v. Notz, Der Dom zu Ratzeburg (1930?) - Ingen af disse Forfattere har behandlet Stoffet tilfredsstillende i kunsthistorisk Henseende.

2) Haupt, Kurze Geschichte des Ziegelbaus (1929) S. 98. - At Domkirkerne i Ratzeburg og Lübeck er omtrent samtidige synes ellers at være almindelig anerkendt. Se Zeitschrift für Geschichte d. Arch VI 77.

10) Haupt, Kurze Geschichte 99, Fig. 45.

11) Mogens Clemmensen, Kallundborg Kirke 8. - Samme Forf. i Aarb. for nord. Oldk. 1922 S. 286.

12) Stiehl, Der Backsteinbau romanischer Zeit (Leipzig 1898) S. 64. Die Bau- und Kunstdenkmähler der Freien und Hansestadt Lübeck III, 1 S. 103. - Kirken i Schönhausen (Mark Brandenburg) fra 1212 viser flere Ligheder med Ratzeburg, se Stiehl, anf. V. S. 67, Fig. 85.

$\left.{ }^{13}\right)$ Beckett, Danmarks Kunst I 208. - Samme Forf. i Aarb. 1908, S. 145 f. - Sønderjyllands Historie I 385 (I a C o u r).

14) Annales Danici 94.

15) Annales Danici 104. 